\title{
Heterotaxy syndrome: a case report ${ }^{*}$
}

Sindrome heterotáxica: relato de caso

Caren Meneghetti Gonçalves ${ }^{1}$, Julia Noschang ${ }^{2}$, Armidio Celeste Bertani da Silva ${ }^{3}$, Renato José Kist de Mello ${ }^{1}$, Sandra Jungblut Schuh ${ }^{4}$, Antonio Carlos Maciel ${ }^{5}$

Gonçalves CM, Noschang J, Silva ACB, Mello RJK, Schuh SJ, Maciel AC. Heterotaxy syndrome: a case report. Radiol Bras. 2014 Jan/Fev;47(1):54-56.

Abstract Heterotaxy syndrome is defined as an abnormal arrangement of some organs and vessels in association with dysmorphism. The authors describe the case of a patient with heterotaxy syndrome with poliesplenia incidentally diagnosed during imaging evaluation (computed tomography and small bowel barium study) of unrelated pathological condition.

Keywords: Heterotaxy syndrome; Polysplenia; Disorders of intestinal rotation; Partial inferior vena cava agenesis; Dorsal pancreas agenesis.

Resu mo Síndrome heterotáxica é definida como um arranjo anormal de alguns órgãos e vasos em associação a dismorfismo. Descrevemos o caso de uma paciente com síndrome heterotáxica diagnosticada incidentalmente durante avaliação por imagem (tomografia computadorizada e radiografia contrastada do intestino delgado) de condição patológica não relacionada.

Unitermos: Síndrome heterotáxica; Poliesplenia; Anomalia de rotação intestinal; Agenesia parcial da veia cava inferior; Agenesia do corpo e cauda do pâncreas.

\section{INTRODUCTION}

Situs or position anomalies are rare, complex and often confusing. Heterotaxy syndrome or situs ambiguns is defined as an abnormal arrangement of organs and vessels associated with dysmorphism, involving a great number of anomalies which do not present as a fixed set of characteristics in all cases. Such a syndrome may be classified into two main subcategories: heterotaxy syndrome with polysplenia and heterotaxy syndrome with asplenia ${ }^{(1,2)}$. Heterotaxy syndrome with polysplenia is characterized by an abnormal arrangement of abdominal and thoracic organs associated with the presence of multiple spleens. Heterotaxy syndrome with asplenia is characterized by ambiguous location of thoracic and abdominal organs and absence of the spleen ${ }^{(2)}$.

In the present report the authors describe the case of a 36 year-old female patient with heterotaxy syndrome with polysplenia incidentally diagnosed during an imaging evalu-

* Study developed at Santa Casa de Misericórdia de Porto Alegre, Porto Alegre, RS, Brazil.

1. MDs, Residents at Unit of Radiology and Imaging Diagnosis, Santa Casa de Misericórdia de Porto Alegre, Porto Alegre, RS, Brazil.

2. Graduate Student of Medicine, Universidade de Passo Fundo, Passo Fundo, RS, Brazil.

3. Graduate Student of Medicine, Universidade Federal de Ciências da Saúde de Porto Alegre, Porto Alegre, RS, Brazil.

4. MD, Radiologist, Unit of Radiology and Imaging Diagnosis, Santa Casa de Misericórdia de Porto Alegre, Porto Alegre, RS, Brazil.

5. MD, Radiologist, Head of Unit of Radiology and Imaging Diagnosis, Hospital Santa Clara and Hospital São Francisco - Santa Casa de Misericórdia de Porto Alegre, Porto Alegre, RS, Brazil.

Mailing Address: Dra. Caren Meneghetti Gonçalves. Serviço de Radiologia e Diagnóstico por Imagem - Hospital Santa Clara da Santa Casa de Misericórdia de Porto Alegre. Rua Professor Annes Dias, 285, Centro. Porto Alegre, RS, Brazil, 90020-090. E-mail: caren.mg@terra.com.br.

Received February 3, 2013. Accepted after revision June 26, 2013. ation of an unrelated pathological condition - nephrolithiasis.

\section{CASE REPORT}

A 36-year-old female patient was incidentally diagnosed with heterotaxy syndrome and polysplenia, four years ago, when she underwent abdominal computed tomography (CT) scan for investigation of renal lithiasis. At that exam, polysplenia, dorsal pancreatic agenesis with hypertrophy of the pancreatic head and uncinate process were found, as well as intestinal rotation anomaly (the large bowel was located at left of the midline and the small bowel at right), and agenesis of the suprarenal segment of the inferior vena cava (IVC) with drainage into the azygos system (Figures 1 and 2). There was a nodule with soft tissue density, measuring $1.8 \mathrm{~cm}$ in diameter, located in the medial arm of the left adrenal gland. The patient was submitted to nodule resection, whose histopathological result was nodular hyperplasia. Considering the possibility of thoracic alterations in patients with heterotaxy syndrome and polysplenia, a chest CT study was performed and demonstrated only enlarged azygos vein. The patient sought medical assistance 20 days ago complaining of diffuse abdominal pain and abdominal distension. Radiological investigation of the small bowel demonstrated absence of intestinal rotation (Figure 3).

\section{DISCUSSION}

The term situs means position or location. Situs solitus represents the usual arrangement of organs and vessels. Situs inversus totalis refers to a mirror image of the habitual location of thoracic and abdominal organs. Any change in the organization of thoracic and abdominal structures other 
than situs solitus or situs inversus, is referred to as situs ambiguus or heterotaxy. Additionally, heterotaxy syndrome is classified as heterotaxy syndrome with polysplenia and heterotaxy syndrome with asplenia. Heterotaxy syndromes are associated with a wide spectrum of changes. Despite of the classification into heterotaxy syndrome with polysplenia and heterotaxy syndrome with asplenia being suggestive of typical anatomical changes of either class, both syndromes involve a great number of findings which are, many times, superimposed. On account of that, some authors suggest that radiological reports should describe the cases individually. Thus, the terminology which best reflects the nonspecificity of the findings of this syndrome consists in not classifying it, but rather referring to it as heterotaxy syndrome followed by a specific description of the anatomy. Heterotaxy syn-

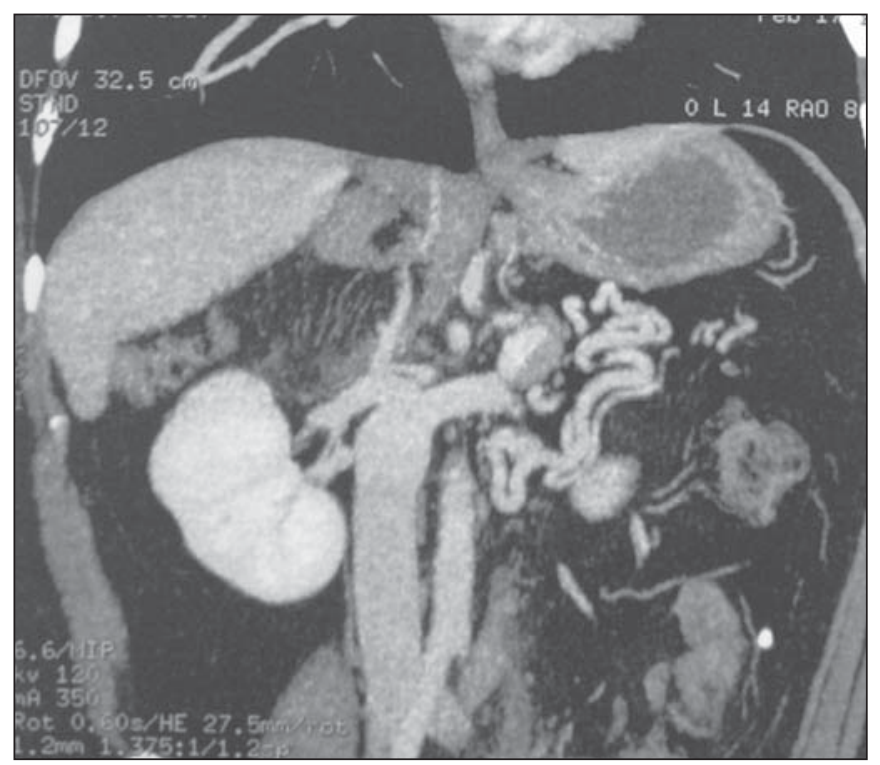

Figure 1. Abdominal computed tomography demonstrating agenesis of the hepatic segment of the inferior vena cava draining into the azygos system. drome may be associated with congenital cardiopathy, interruption of IVC with azygos continuation, multiple spleens, intestinal malrotation and pancreatic changes ${ }^{(1-3)}$.

Although heterotaxy syndrome with polysplenia is associated with multiple spleens in most patients, some patients may present with only a lobulated spleen or even a normal spleen $^{(3)}$.

Patients with heterotaxy syndrome present a prevalence of congenital cardiac diseases in $50 \%$ to $100 \%$ of the cases ${ }^{(4,5)}$. Heterotaxy syndrome with asplenia is associated with congenital cardiac disease in $99 \%$ to $100 \%$ of the cases and it is usually of greater severity as compared with heterotaxy syndrome with polysplenia. Thus, the higher frequency of incidental diagnoses of heterotaxy syndrome with polysplenia in adulthood is explained ${ }^{(5)}$.

The association of polysplenia with intestinal rotation anomalies is frequently found ${ }^{(1)}$. The most important abnormalities of intestinal rotation and fixation are: non rotation, malrotation and inverted rotation. Intestinal non rotation as described in the present case is generally asymptomatic ${ }^{(6)}$. In a case series, intestinal rotation anomalies were observed in seven of eight patients with polysplenia. None of the patients in that series had a history of intestinal obstruction related to the abnormal intestinal rotation ${ }^{(2)}$.

Agenesis of the suprarenal portion of IVC (hepatic segment) with continuation through the azygos system by means of a persistent right supracardinal vein is a rare anomaly with a prevalence of $0.10 \%^{(7)}$. In such cases, the azygos vein drains into the superior vena cava. In those situations, there is only a short hepatic segment of the IVC cranial to the hepatic veins confluence, normally draining into the right atrium. In general, patients are asymptomatic. However, there may be association between such finding and heterotaxy syndrome, and interrupted IVC is one of the most frequent findings in cases of heterotaxy syndrome with polysplenia ${ }^{(8)}$.

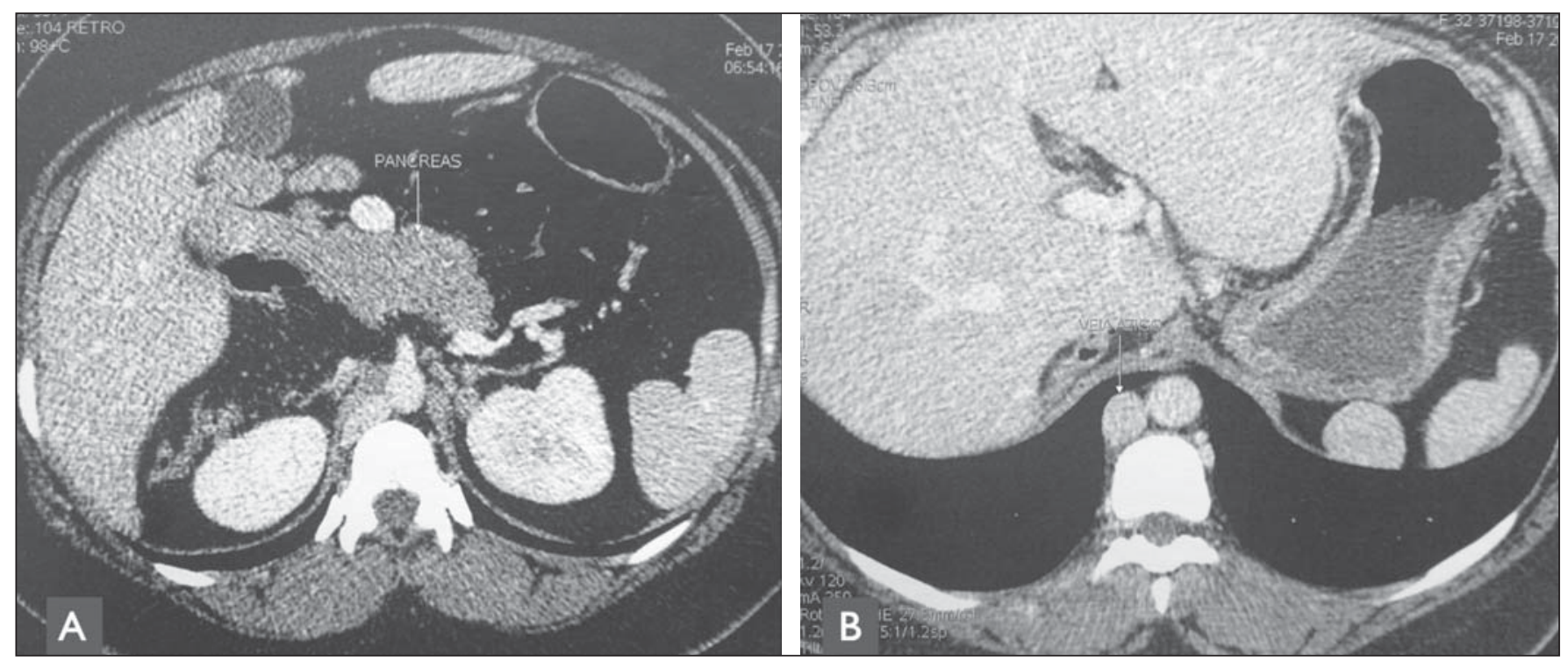

Figure 2. Axial abdominal CT image. A: Agenesis of the dorsal pancreas with hypertrophy of the head of the pancreas and uncinate process. B: Multiple spleens, agenesis of the hepatic segment of the inferior vena cava and enlarged azygos vein are identified. 

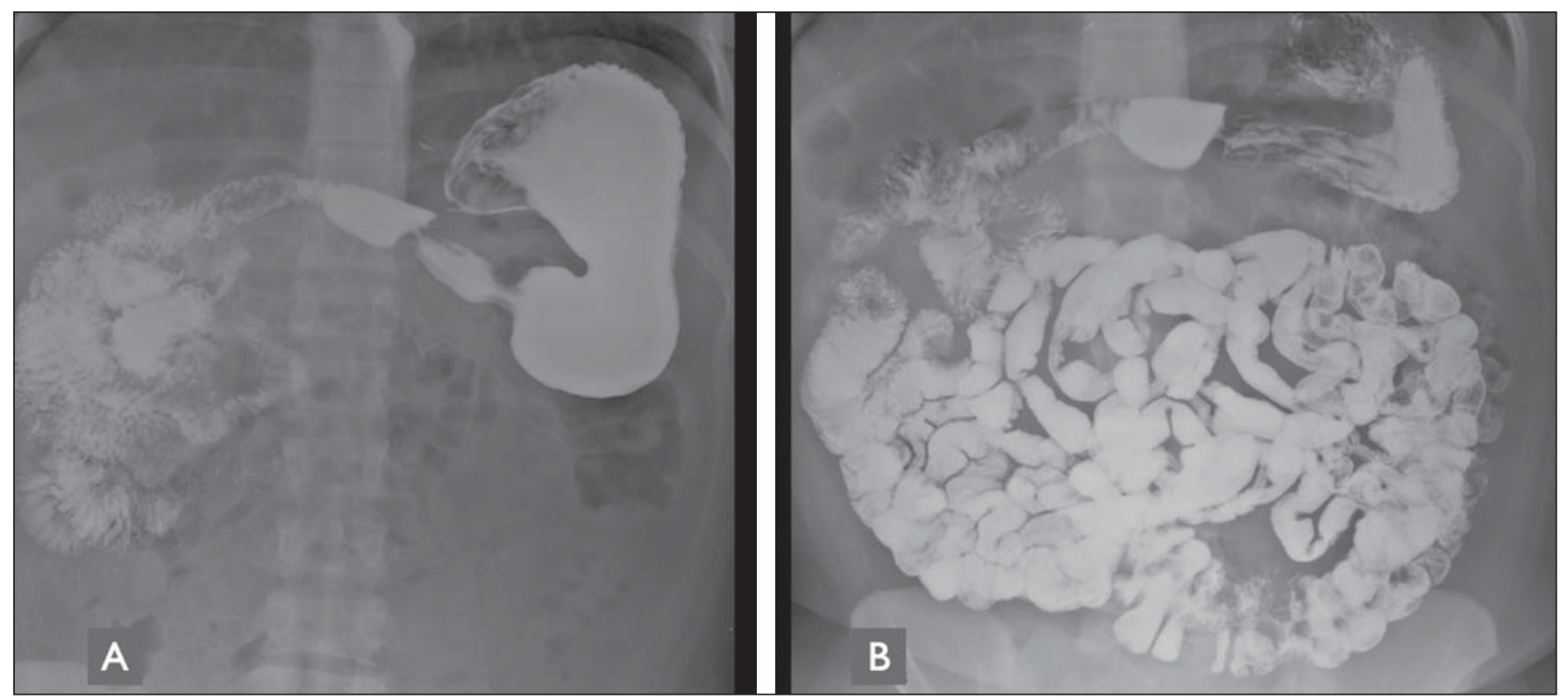

Figure 3. Contrast-enhanced radiography of small bowel (contrast medium: barium sulfate). A: The jejunal loops are located in the right hemiabdomen. Presence of metal clips - resection of left adrenal gland. B: Absence of intestinal rotation is observed. The small bowel loops are found at the right and the large bowel at the left.

Pancreatic anomalies are well known in heterotaxy syndrome with polysplenia. In the normal embryonic development, the pancreas results from a ventral bud (uncinate process and head) and a dorsal bud (body and tail). Most times, there is agenesis of the dorsal portion. The dorsal pancreas and the spleen develop in the dorsal mesentery, thus concomitant anomalies may be expected ${ }^{(9)}$.

\section{CONCLUSION}

Although heterotaxy syndrome is a rare congenital disorder, the radiological recognition of the extensive variety of presentations, as well as their appropriate description, represent the most indicated form of evaluating those cases at high risk of complications caused by the anatomical alterations.

\section{REFERENCES}

1. Applegate KE, Goske MJ, Pierce G, et al. Situs revisited: imaging of the heterotaxy syndrome. Radiographics. 1999;19:837-54.
2. Fulcher AS, Turner MA. Abdominal manifestations of situs anomalies in adults. Radiographics. 2002;22:1439-56.

3. Teles A, Dinis MJ, Ferreira L, et al. Anomalias da lateralização: dois casos clínicos. Nascer e Crescer. 2010;XIX:74-7.

4. Peoples WM, Moller JH, Edwards JE. Polysplenia: a review of 146 cases. Pediatr Cardiol. 1983;4:129-37.

5. Tonkin IL. The definition of cardiac malpositions with echocardiography and computed tomography. In: Friedman WF, Higgins CB, editors. Pediatric cardiac imaging. Philadelphia: Saunders; 1984. p. $157-87$.

6. Berrocal T, Lamas M, Gutiérrez J, et al. Congenital anomalies of the small intestine, colon, and rectum. Radiographics. 1999;19:1219-36.

7. Koc Z, Oguzkurt L. Interruption or congenital stenosis of the inferior vena cava: prevalence, imaging, and clinical findings. Eur J Radiol. 2007;62:257-66.

8. Fernandes AM, Rahi V, Yamrozik J, et al. Ressonância magnética cardiovascular em veia cava inferior interrompida não prevista. Arq Bras Cardiol. 2012;98:e24-e27.

9. Maier M, Wiesner W, Mengiardi B. Annular pancreas and agenesis of the dorsal Pancreas in a patient with polysplenia syndrome. AJR Am J Roentgenol. 2007;188:W150-W153. 